Journal of Case Reports 2017;7(1):61-64

\title{
A Fatal Non-traumatic Rupture of Splenic Hemangiomatosis
}

\author{
SS Soyemi, OO Oyewole, FE Emiogun, UV Okeke, OO Williams, OO Kila, OF Osuolale \\ Department of Pathology and Forensic Medicine, Lagos State University Teaching Hospital, Ikeja, Lagos, Nigeria.
}

\section{Corresponding Author:}

Dr. Soyemi S. S.

Email: soyemisunday@yahoo.com

This is an Open Access article distributed under the terms of the Creative Commons Attribution License (creativecommons.org/ licenses/by/3.0).

Received

Accepted

Published

July 15,2016

December 23, 2016

February 15, 2017

\begin{abstract}
Background: Isolated diffuse splenic hemangiomatosis is a rare condition. Case Report: We report a case of a 62-year old male accountant who had a sudden collapse while returning from work. Massive hemoperitoneum without splenomegaly was discovered clinically and further supported with the findings of ultrasonography. He died in transit to the theatre while being prepared for splenectomy. There was no history of fall or trauma to the abdomen. Past medical history was also not contributory. Autopsy showed hematoma and rent on diaphragmatic surface of spleen. Microscopic examination confirmed diffuse hemangiomatosis of the spleen. Conclusion: This case presents a situation in which death was natural but could have been taken for a homicide if the autopsy had not been done. Splenic hemangiomatosis could be clinically silent for years in the absence of other usual accompanying features.
\end{abstract}

Keywords: Autopsy, Hemangioma, Hemoperitoneum, Splenectomy, Splenomegaly.

\section{Introduction}

The most common primary benign neoplasm of the spleen is cavernous hemangioma. Although, entirely benign, it can be fatal [1]. Isolated diffuse splenic hemangiomatosis is characterized by replacement of entire parenchyma by a proliferation of neoplastic blood vessels [1,2]. Cases of splenic hemangiomatosis are infrequent but have been reported from various parts of world [3-13]. Kasabach-Merritt syndrome (KMS), also known as hemangioma with thrombocytopenia is a rare disease of infants, has an association with splenic hemangiomatosis [15]. The most common documented complication is hemoperitoneum following a rupture.

\section{Case Report}

We report a case of a 62-year old male accountant who had previously been apparently healthy and suddenly collapsed at home after returning from work. He was rushed to a private hospital where he had series of investigations including abdominal ultrasound. Massive hemoperitoneum without splenomegaly was discovered clinically and further supported by the findings on ultrasonography. $\mathrm{He}$ had blood transfusion and died in-transit to theatre while being prepared for splenectomy. There was no history of fall or trauma to the abdomen. Past medical history revealed that patient was neither hypertensive nor diabetic. He had never been hospitalized and only had past history of malaria which was treated by the use of oral antimalarial drugs.

At autopsy, there was no evidence of trauma or violence on the body. Few skin tags were however noted on the back. On opening up, the various organs were in their normal anatomical positions. There was no bruise on the abdominal wall to rule out blunt force trauma. The cardiovascular system was essentially unremarkable. Although fatty streaks were seen on the intima of aorta, abdominal aorta and its branches (especially at the bifurcation), no aneurysmal tear was found. Visceral injuries were also sought for and also none was found. 
The striking picture was that of a rent which measures $5.5 \mathrm{~cm}$ on the diaphragmatic surface of the spleen with a weight of 200 gm and measures $11.0 \times 6.3 \times 3.0 \mathrm{~cm}$ [Fig.1,2]. Closer examination underneath the rent revealed multiple dilated tiny cavities. There was $2500 \mathrm{ml}$ of hemoperitoneum [Fig.3,4]. Routine samples of organs including the spleen were taken and fixed in $10 \%$ formalin for microscopic examination.

Microscopic examination of the spleen revealed proliferating mostly large vascular channels containing blood and lined by flattened endothelial cells. In between these neoplastic vascular channels were areas of old and mostly recent hemorrhage with few scattered lymphoid follicles. Microscopic sections of all the other organs were essentially unremarkable. Death was ascribed to massive hemoperitoneum following spontaneous rupture of isolated diffuse hemangiomatosis of the spleen.

\section{Discussion}

This rare disease and its complication bring to the fore the value of conducting post-mortem examination on sudden unexpected deaths. A suspicion of blunt force trauma was suspected by clinicians and deceased family. It was against this background that the postmortem examination was requested for by the family. The final diagnosis of spontaneous rupture of isolated diffuse hemangiomatosis eventually resolved the doubt. In our patient the rare complication of hemoperitoneum can be misdiagnosed to be due to a blunt force trauma to the abdomen which can result in a medicolegal case. This however was not the case as a postmortem examination and histology was done which resulted in the identification of this rare disease in Africa.

Patients with this rare disease are often asymptomatic but sometimes present with complications such as anemia [8,11], thrombocytopenia [11], giant splenomegaly [11],

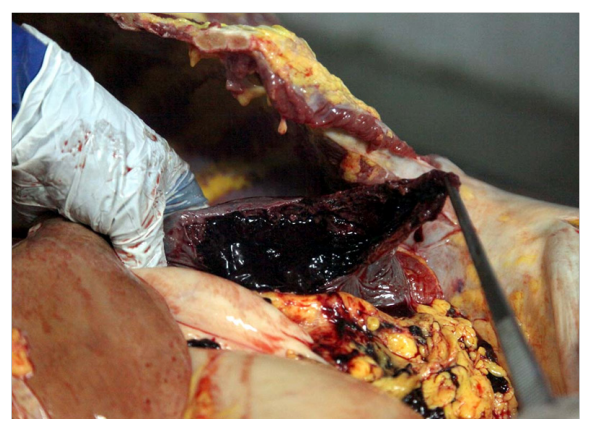

Fig.1: Ruptured spleen before removal from the body at autopsy.

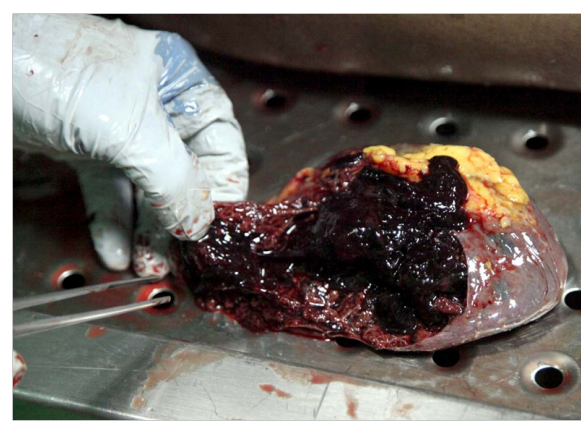

Fig.2: Ruptured spleen at autopsy.

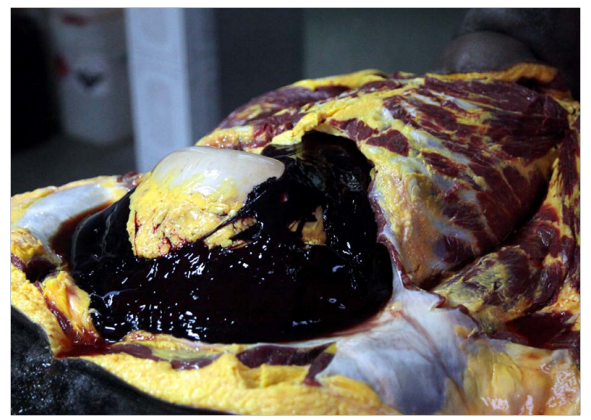

Fig.3: Massive hemoperitoneum on opening the body on the autopsy table.

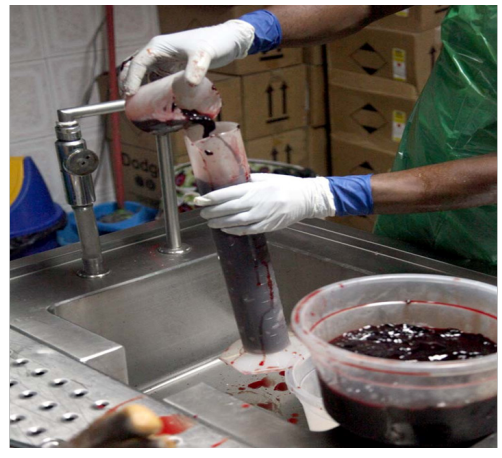

Fig.4: Hemoperitoneum being measured at autopsy. 
portal hypertension and esophageal varices [10]. The hemoperitoneum seen in this index case is a rare complication. This has been previously documented in conjunction with Kasabach-Merritt syndrome [15]. The absence of other complications strongly suggests that the splenic tumor might have been the only pathology in this patient and again may likely explain why the disease was not detected in the past years. A future study that would attempt to find out other possible indicators (or other syndromic features) in hemangioma of vital organs such as liver and spleen will be a welcome development and should be encouraged.

Routine radiographic investigation of the abdomen also has its own limitation. A plain abdominal radiograph is non-sensitive and nonspecific as it shows only calcification in the left hypochondriac region and features of splenomegaly [16]. The use of liver-spleen ultrasound, abdominal sonography and abdominal Computed Tomography demonstrate only an enlarged spleen with a diffuse parenchymal textural abnormality. Only the use of splenic angiography will give a definitive pattern of diffuse hemangiomatosis [17,18]. Splenic and other vital organs angiography should therefore be recommended if hemangiomatosis is suspected.

\section{Conclusion}

This case presents a situation in which the manner of death was natural but could have been taken for a homicide if the autopsy had not been done. Again, it has shown that splenic hemangiomatosis could be clinically silent for years in the absence of other usual accompanying features highlighted above. Finally, splenic and other vital organ angiography should in the opinion of the authors are recommended at least once in lifetime for an individual whose initial investigations are suggestive of splenic hemaniomatosis as part of the comprehensive medical examination so as to detect imminent fatal rupture.
Acknowledgements: We thank the morticians who assisted during the post-mortem examination and the histotechnologist who prepared the slides.

Contributors: SSS is a Lecturer and consultant pathologist who supervised the autopsy, performed the literature search and prepared the manuscript. OOO and OOK are senior registrars who performed the autopsy, grossed the specimens and reported the microscopic findings. OOW and OFO took the photographs and contributed to the literature search. Funding: None; Competing interests: None stated.

\section{References}

1. Kutok JL, Fletcher CDM. Splenic Vascular tumours. Semin Diagn Pathol. 2003;20:128-139

2. Steininger H, Pfofe D, Marguardt, Sauer H, Markwat R. Isolated diffuse haemangiomatosis of the spleen: a case report and review of literature. Pathol Res Pract. 2004;200:479-485.

3. Ambrosio MR, Rocca BJ, Mari ND, Ambrosio A, Lazzi S. Multifocal capillary haemangioma (haemangiomatosis) of the spleen. Tumori. 2012;98:e22-e26.

4. Atasoy P, Bozdogan O, Erekul S. Diffuse haemangiomatosis of the spleen associated with pregnancy. A case report. Turk J Cancer. 2004;34:85-87.

5. Eliyatkin N, Kececi SD, Sezgin A, Postaci H, Tekeli T, Denecil AG. Diffuse haemangiomatosis of the spleen- a case report. Aegean Pathology Journal. 2006;3:14-17.

6. Dufau JP, Le Tourneau A, Auodin, J, Delmer A, Dic bold J. Isolated diffuse haemangiomatosis of the spleen with Kasabach - Meritt like syndrome. Histopathology. 1999;35:337-344.

7. Louise TH, Saunders JM, Stephenson JS, Harbour LN, Keneth L. Ford 111. Splenic haemangiomatosis. Pro (Bayl Univ Med Cent). 2011;24:356-358.

8. Ruck P, Horny HP, Lori JC, Bajin Ski R, Kaiserling E. Difuse sinusoidal heamangiomatosis of the spleen. A case report with enzyme- histochemical, immunohistochemical and electron microscopic findings. Pathol Res Pract. 1994;190:708-714.

9. Radhi JM, Wallis JP, Marsy H. Haemolytic anaemia associated with splenic haemangimatosis. Postgraduate Medical Journal. 1988;64:152-154.

10. Pitlik S, Cohen L, Hadar H, Srulijes C, Rosenfield JB. Portal hypertension and oesophageal varices in haemangiomatosis of the spleen. Gastroenterology. 1977;72: 937-940.

11. Makino I, Tajima H, Kitagawa H, Nalagawa H, Ohta T. A rare case of haemagiomatosis of the spleen and intrapancreatic accessory spleen. Abdom Imaging. 2014;39(6):1169-1174. 
12. Shiran A, Naschita JE, Yeshurun D, Misselevitch I, Boss JH. Diffuse haemangiomatosis of the spleen: splenic haemangiomatosis presenting with giant splenomegaly, anaemia and thrombocytopenia. Am J Gastroenterol. 1990;85(11):1515-1517.

13. Tang JY, Chen J, Pan C, Yin MZ, Zhu M. Diffuse cavernous haemagoima of the spleen with Kasabach- Meritt syndrome misdiagnosed as idiopathic thrombocytopenia in a child. World J Pediatr. 2008;4:227-230.

14. Dixit VK, Sharma H, Ratnaka KS, Murthy VS. Spleenic haemangiomatosis with osseous involvement. Indian $\mathrm{J}$ Gastroenterol. 1993;12:105-106.
15. Shanberge JN, Tanaka K, Gruhi MC. Chronic consumption coagulopathy due to haemagiomatosis transformation of the spleen. Am J Clin Pathol. 1971;56(6):723-729.

16. Geogina W Hall. Kasabach - Meritt syndrome. British Journal of haematology. 2001;112;851-862.

17. Weerakkody Y, Venkatesh M, et al. Splenic haemangiomatosis. Available at: https://radiopaedia.org/ articles/splenic-haemangiomatosis. Accessed on: July 15, 2016.

18. Rose SC, Kumpe DA, Manco-johnson ML. Radiographic appearance of diffuse splenic haemangiomatosis. Gastrointest Radiol. 1986;11:342-346. 